(6)

\section{OPEN ACCESS}

- Additional material is published online only. To view please visit the journal online (http://dx.doi.org/10.1136/ archdischild-2014-306853).

Academic Unit of Child Health, University of Nottingham, Derbyshire Children's Hospital, Derby, UK

\section{Correspondence to} Emeritus Professor Imti Choonara, Academic Unit of Child Health, The Medical School, University of Nottingham, Derbyshire Children's Hospital, Uttoxeter Road, Derby DE22 3DT, UK; imti.choonara@nottingham.ac. uk

Received 27 May 2014 Revised 18 August 2014 Accepted 19 August 2014

Published Online First

8 September 2014

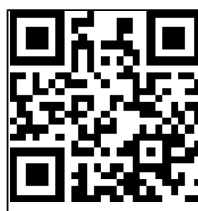

\title{
Paediatric clinical pharmacology in the UK
}

\author{
Imti Choonara, Helen Sammons
}

\section{ABSTRACT}

Paediatric clinical pharmacology is the scientific study of medicines in children and is a relatively new subspecialty in paediatrics in the UK. Training encompasses both the study of the effectiveness of drugs in children (clinical trials) and aspects of drug toxicity (pharmacovigilance). Ethical issues in relation to clinical trials and also studies of the pharmacokinetics and drug metabolism in children are crucial. Paediatric patients require formulations that young children in particular are able to take. The scientific evidence generated from clinical trials, pharmacokinetic studies and studies of drug toxicity all need to be applied in order to ensure that medicines are used rationally in children.

Drug therapy is an essential component in the management of children. The scientific study of medicines in children is known as paediatric clinical pharmacology and is a relatively new subspecialty in the UK. ${ }^{1}$ It was recognised as a new subspecialty in paediatrics in $2003 .^{2}$ Since then, accredited paediatric clinical pharmacologists have been appointed in Derby, Newcastle, Liverpool and the Medicines Health Regulatory Agency. There is increasing recognition that medicines used for children should be scientifically evaluated for both efficacy and toxicity. ${ }^{1}$

Paediatric clinical pharmacologists in conjunction with other disciplines and, in particular, paediatric clinical pharmacists, have been instrumental in several major initiatives in relation to improving the management of children with drugs. These include the following:

- The British National Formulary for Children. ${ }^{3}$

- European legislation encouraging clinical trials of medicines in children. ${ }^{4}$

- The establishment of the Medicines for Children Research Network. ${ }^{5}$

The UK is one of the few countries in the world which has both a recognised training programme and accreditation. ${ }^{6}{ }^{7}$ Other countries with a training programme include Australia, Canada and the USA. ${ }^{7}$ Within Europe, several countries have either trainees or a training programme (Finland, France, Germany, Italy, The Netherlands, Sweden). ${ }^{6}$ There have been discussions internationally (through the European Society for Developmental Perinatal and Paediatric Pharmacology and the EU FP7-funded programme Global Research in Paediatrics) to share experiences and to obtain agreement on an international training programme in paediatric clinical pharmacology. There have also been informal exchanges between training centres in paediatric clinical pharmacology whereby trainees have gained valuable experience in a different country. These exchanges have resulted in both benefits to the individual trainee as also to the training centres which have usually resulted in collaboration in European research projects.

Within the UK, the training programme is for medical graduates who have completed a minimum of 2 years of general professional training and have been accepted onto a training programme in paediatrics. They need to have completed 2 years of core training in paediatrics before undertaking a 3-year national grid speciality training programme in paediatric clinical pharmacology. We, therefore, feel it would be worthwhile highlighting the training programme and its relevance to doctors training in paediatrics in particular, but also to other health professionals.

The competencies for the training programme are available as online supplementary appendix 1 . We wish to expand upon the scientific rationale for these competencies.

\section{CLINICAL TRIALS}

It is appropriate to scientifically evaluate medicines that are likely to be of benefit to children in a clinical trial. Previously, many medicines were not studied in children and children were deprived of the evidence base to use medicines rationally. ${ }^{8}$ The new European legislation, introduced in 2007, recognises the need to study all new medicines where appropriate, but does not endorse the study of numerous me-too drugs in children. Clinical trials in paediatric patients invariably need to be less invasive than clinical trials in healthy adult volunteers. Blood sampling and other invasive procedures should be kept to the minimum or avoided entirely if not clinically relevant. ${ }^{9}$

Safety in clinical trials in children is essential. Unfortunately, there have been clinical trials performed in children where children have experienced significant toxicity because the investigators did not fully consider safety issues first. ${ }^{10}$ Previously, many clinical trials in children did not have an independent safety monitoring board/data monitoring committee. ${ }^{11}{ }^{12}$ Fortunately, these are now mandatory for clinical trials of medicines in paediatric patients in the UK.

\section{PHARMACOKINETICS}

Pharmacokinetics is the scientific study of how the body handles a medicine. There are three fundamental parameters that are determined in pharmacokinetic studies. ${ }^{13}$

- Clearance usually relates to plasma, and is the volume of plasma that is completely cleared of drug per unit time, and in children is usually expressed in relation to body weight.

- Volume of distribution is the apparent volume into which the drug would have to distribute to achieve the measured concentration. ${ }^{13}$ 
- The elimination half-life is the time taken for $50 \%$ of the drug to be eliminated from the body.

The elimination half-life is the parameter that is most frequently used by clinicians. Historically, pharmacokinetic studies involved the collection of numerous (often 15-20) blood samples from healthy adult volunteers. This is not ethical in paediatric patients for two reasons. First, one cannot administer a medicine to a healthy child as one does with healthy adult volunteers. Second, most parents would not give consent for their child to have 12 separate venepunctures for a pharmacokinetic study.

The most common approach for pharmacokinetic studies in children is to use a population pharmacokinetic approach. This involves the study of a larger number of children but with the collection of only a few blood samples from each individual child. ${ }^{14} 15$ Non-invasive methods such as the caffeine breath test have also been used to study drug metabolism in children. ${ }^{16}$ The caffeine breath test is expensive and involves the use of a stable isotope but has the advantage that no blood samples are collected at all.

\section{ETHICS}

Ethical issues in relation to both clinical trials and pharmacokinetic studies in paediatric patients of all ages are paramount. Healthy children should not be recruited as volunteers for pharmacokinetic studies, except in certain vaccine studies, as is the standard approach to pharmacokinetic studies in adults. It is more appropriate to perform pharmacokinetic studies in paediatric patients who will be receiving the medicine therapeutically. There is now greater awareness of the need to obtain assent from children and young people alongside the formal, legal parental consent. ${ }^{17}$

\section{DRUG METABOLISM}

The major metabolic pathways involved in drug metabolism include the cytochrome P450 system of which the most important are CYP3A4 and CYP1A2. ${ }^{18-20}$ The activity of these different metabolic pathways is often different in paediatric patients to that in adults. CYP3A4 is the most important liver enzyme responsible for drug metabolism. ${ }^{19}$ Frequently used medicines in children that are dependent upon CYP3A4 for its metabolic breakdown are listed in table $1 .^{19}{ }^{20}$ CYP3A4 activity is very low in neonates. The activity increases in the first year of life and is greater in infants and children than adolescents and adults. ${ }^{19}$

CYP1A2 is responsible for the metabolism of caffeine and theophylline. Like CYP3A4, its activity is very low at birth but

Table 1 Enzymes responsible for drug metabolism

\begin{tabular}{lll}
\hline Enzyme & Drugs metabolised & \\
\hline CYP3A4 & Alfentanil & Ketoconazole \\
& Carbamazepine & Midazolam \\
& Ciclosporin & Nifedipine \\
& Erythmocycin & Rifampicin \\
& Ethosuximide & Tacrolimus \\
& Fentanyl & \\
CYP1A2 & Caffeine & Theophylline \\
CYP2B6 & Cyclophosphamide & Propofol \\
CYP2C9 & Ibuprofen & Phenytoin \\
CYPC2C19 & Diazepam & Omeprazole \\
CYP2D6 & Codeine & Fluoxetine \\
\hline
\end{tabular}

increases during the first year of life. ${ }^{20}$ Other cytochrome enzymes associated with drug metabolism include CYP2B6, CYP2C9, CYP2C19 and CYP2D6. The activity of all these enzymes is decreased in the neonatal period and usually increases in infancy. ${ }^{20}$

Phase 2 metabolic pathways include glucuronidation and sulfation. $^{21} 22$ The uridine 5'-diphospho-glucuronyl transferases are responsible for glucuronidation. Some drugs, such as codeine and propofol, undergo glucuronidation as well as oxidation by different cytochromes. Other drugs, such as morphine and paracetamol, undergo predominately glucuronidation. ${ }^{15} 22$ Glucuronidation is reduced in the neonatal period and slowly increases during infancy. Sulphation is a relatively minor pathway for drug metabolism but may be increased in the neonatal period. Paracetamol undergoes considerable sulphation in prepubertal children and this is thought to be responsible for the reduced toxicity following overdose in young children.

Different metabolic pathways develop at different rates. These are illustrated in table 2 , which shows the relative contribution of each metabolic pathway at different ages. Sulphation contributes proportionately more in the neonatal period due to the immaturity of the other enzyme systems which increase in infancy. It is important to recognise, however, that this is a generalisation and that each individual drug will have a different rate of development. The aim of increasing our understanding of drug metabolism and pharmacokinetics is to ensure that we use appropriate doses of different medicines in different groups of paediatric patients; it is not a one-size-fits-all for children.

\section{PHARMACODYNAMICS}

Pharmacodynamics is the scientific study of the effect that a drug has on the human body. Whereas differences in drug metabolism and pharmacokinetics in paediatric patients have been studied by many groups, there has been far less work on differences in paediatric patients in relation to pharmacodynamics. $^{23}$ Measuring the effect of drugs, such as antiepileptic drugs or antihypertensives, is easy in patients of all ages. Measuring the effect of analgesic agents, however, is more difficult especially in young children and neonates who are unable to respond to direct questioning. In these circumstances, one needs validated pain scales in order to accurately assess pharmacodynamic effect.

\section{PHARMACOGENETICS}

Genetic factors have a major impact on both drug metabolism and the development of drug receptors. ${ }^{24}$ The study of pharmacogenetics in paediatric patients is complicated by the need to take into account differences in the ontogeny of drug metabolic pathways and development of receptors. ${ }^{18}$ The interrelationship between pharmacogenetics, efficacy and toxicity have been studied in relation to the cytotoxic drug 6-mercaptopurine. $^{25}$ One of the enzymes responsible for the metabolism of

\begin{tabular}{lllll}
\multicolumn{7}{l}{ Table 2} & Drug metabolism and age & & \\
\hline Age & CYP3A4 & CYP1A2 & Glucuronidation & Sulphation \\
\hline Preterm neonates & + & + & + & ++ \\
Term neonates & + & + & + & +++ \\
Infants & +++ & ++ & ++ & ++ \\
Children & +++ & +++ & +++ & + \\
Adolescents & ++ & +++ & +++ & + \\
\hline
\end{tabular}


6-mercaptopurine is thiopurine S-methyltransferase. Individuals with reduced activity of this enzyme, who are treated with standard doses, are more likely to develop bone marrow suppression $^{25}$ and so all children now starting chemotherapy for acute lymphoblastic leukaemia are tested to prevent this toxicity in susceptible individuals. By contrast, those with increased activity are at greater risk of hepatotoxicity, and the drug is less likely to be effective in the treatment of acute lymphoblastic leukaemia because of the more rapid metabolism. ${ }^{25}$

\section{DRUG TOXICITY}

Children are prone to many of the side effects of medicines that occur in adults. They may also experience additional side effects due to direct toxicity on organs that are developing. Growth suppression due to the administration of corticosteroids is a drug toxicity specific to paediatric patients. Some adverse drug reactions are more common in paediatric patients, for example, the hepatotoxicity due to sodium valproate and the propofol infusion syndrome following its use as a sedative. ${ }^{26}$ Other adverse drug reactions only occur in specific age groups, for example, kernicterus in neonates or calcium precipitation following concomitant administration of ceftriaxone and intravenous calcium-containing solutions in neonates and young children. It is important to understand the mechanism for adverse drug reactions in children. If one understands the pathophysiology then this is often beneficial in trying to prevent future adverse drug reactions occurring. Some of the adverse drug reactions that occur more frequently in paediatric patients are described in table 3 alongside the postulated mechanisms.

Pharmacovigilance is the scientific study of the safety of medicines. Regulatory agencies have usually focused their efforts on drug safety in the elderly who often have impaired hepatic and renal function and are exposed to polypharmacy. The elderly are, therefore, more likely to experience drug toxicity than paediatric patients who are healthier. Pharmacovigilance in children, however, is important for several reasons. First, children, like adults, experience a wide range of adverse drug reactions ${ }^{27}$ but may also experience different reactions as well. Additionally, most adverse drug reactions are either undetected due to poor recognition or unreported. Education of health professionals about the importance of pharmacovigilance has been shown to be effective in increasing reporting of adverse drug reactions. ${ }^{28}$

\begin{tabular}{|c|c|c|c|}
\hline Age group & Drug & ADR & Mechanism \\
\hline Neonates & Sulphonamide & Kernicterus & $\begin{array}{l}\text { Highly protein } \\
\text { bound drug } \\
\text { displaces bilirubin }\end{array}$ \\
\hline Neonates & Chloramphenicol & $\begin{array}{l}\text { Grey baby } \\
\text { syndrome }\end{array}$ & $\begin{array}{l}\text { Impaired } \\
\text { metabolism }\end{array}$ \\
\hline $\begin{array}{l}\text { Neonates and } \\
\text { young infants }\end{array}$ & $\begin{array}{l}\text { Ceftriaxone- } \\
\text { calcium solutions }\end{array}$ & $\begin{array}{l}\text { Calcium } \\
\text { precipitation in } \\
\text { lungs }\end{array}$ & Unknown \\
\hline $\begin{array}{l}\text { Infants and } \\
\text { young children }\end{array}$ & Sodium valproate & Hepatotoxicity & $\begin{array}{l}\text { Abnormal } \\
\text { metabolism? }\end{array}$ \\
\hline Children & Propofol & $\begin{array}{l}\text { Propofol infusion } \\
\text { syndrome }\end{array}$ & $\begin{array}{l}\text { Unknown, but } \\
\text { thought to be dose } \\
\text { related }\end{array}$ \\
\hline Children & Vigabatrin & $\begin{array}{l}\text { Visual field } \\
\text { defects }\end{array}$ & Unknown \\
\hline Adolescents & Metoclopramide & Dystonia & Unknown \\
\hline
\end{tabular}

\section{REGULATORY}

The inter-relationship between the pharmaceutical industry, regulatory agents, patients and health professionals is crucial for the safe and effective use of medicines in children. Historically, children have often been neglected in many societies and the situation is similar with regards to drug therapy in paediatric patients. Legislative changes have been introduced in both the USA and Europe in response to scientific studies documenting the extent of off-label and unlicensed drug use in paediatric patients. $^{29}$ These legislative changes have encouraged the pharmaceutical industry to study medicines in children by providing a 6-month patent extension for new medicines. For medicines that are no longer patent protected, a period of market exclusivity (a Paediatric Use Marketing Authorisation-PUMA) can be provided. We now have more clinical trials in paediatric patients, but concerns have been raised that the medicines that are studied are those that bring the greatest financial benefit to the pharmaceutical industry rather than medicines that will significantly benefit paediatric patients clinically. ${ }^{30}$

\section{FORMULATIONS}

The development of paediatric formulations is an example of how children have historically been neglected. Paediatric formulations are more expensive to develop, and it has only been in recent years that there have been major advances in relation to different types of formulations that may be appropriate for young children in particular. ${ }^{31}$ The lack of appropriate formulations may be a contributory factor to medication errors. Tenfold errors are far more common in paediatric patients than in adults. This is a particular problem in neonates where a single vial, such as morphine, will contain more than 10 times the amount of drug that an individual neonate requires. ${ }^{32}$

\section{RATIONAL USE OF MEDICINES}

The justification for promoting clinical trials in paediatric patients is to ensure that they receive medicines that have been scientifically tested for both efficacy and safety. Once scientific evidence is published, health professionals have an obligation to ensure that they use this information. Unfortunately, the scientific study of the rational use of medicines has been a neglected area of research. Development of formularies, such as the British National Formulary for Children alongside guidelines by National Institute of Clinical Excellence and Scottish Intercollegiate Guidelines Network are positive steps in trying to ensure that medicines are used in a rational and appropriate manner. Unfortunately, irrational use of medicines appears to be a problem in high-income countries as well as low-income countries. $^{33} 34$ Pharmacoepidemiological studies of drug usage in children are invaluable in determining whether medicines are prescribed rationally or not in paediatric patients. ${ }^{35-37}$ It is in this area that paediatric clinical pharmacologists can play an important role. The rational use of medicines should ideally result in financial benefits for governments and health systems, but most importantly improve patient outcomes and, in particular, reduce drug toxicity.

\section{FUTURE DEVELOPMENTS}

The number of paediatric clinical pharmacologists in the UK remains low despite the welcome addition of four accredited individuals. Paediatric clinical pharmacologists can play a valuable role both locally and nationally. They can play a crucial role locally on drug and therapeutic committees ensuring that only medicines that are likely to benefit children are introduced onto 
the hospital formulary. In conjunction with pharmacy departments, they can ensure that guidelines are evidence based and respond to national safety alerts that are medication related, such as the MHRA guidance for codeine use in children. Their benefits in relation to research are not restricted to facilitating clinical trials. They can contribute nationally and in Europe to drug formularies (such as the British National Formulary for Children), national prescribing committees and regulatory bodies. A role in the guidance of safe prescribing and the rational use of medicines is well established. ${ }^{3}{ }^{14}{ }^{34}$ It is to be hoped that collaboration between paediatric clinical pharmacologists in different countries continues, with further developments in training, and that the interchange between training centres in paediatric clinical pharmacology, especially within Europe, continues. ${ }^{38-40}$

\section{CONCLUSIONS}

It is now widely accepted that medicines used in children need to be evaluated scientifically for both efficacy and toxicity. Doctors who wish to focus on studying medicines in children now have the possibility to train in paediatric clinical pharmacology. There have been major advances in clinical trials of medicines in paediatric patients. The challenge in the future is ensuring that the scientific evidence generated by clinical trials is used to ensure that medicines are prescribed in a rational manner.

Contributors Both authors have written and approved the paper.

Competing interests HS is CSAC Chair in Paediatric Clinical Pharmacology.

Provenance and peer review Not commissioned; externally peer reviewed.

Open Access This is an Open Access article distributed in accordance with the Creative Commons Attribution Non Commercial (CC BY-NC 4.0) license, which permits others to distribute, remix, adapt, build upon this work non-commercially, and license their derivative works on different terms, provided the original work is properly cited and the use is non-commercial. See: http://creativecommons.org/ licenses/by-nc/4.0/

\section{REFERENCES}

1 Hoppu K. Paediatric clinical pharmacology —at the beginning of a new era. Eur J Clin Pharmacol 2008:64:201-5.

2 Choonara I, Dewit O, Harrop E, et al. Training in paediatric clinical pharmacology in the UK. B J Clin Pharmacol 2004;58:217-18.

3 Elias-Jones A, Rylance $\mathrm{G}$. The launch of the British National Formulary for Children. Arch Dis Child 2005:90:997-8.

4 Choonara I. Regulation of drugs for children in Europe. BMJ 2007;335:1221-2.

5 Smyth RL, Edwards AD. A major new initiative to improve treatment for children. Arch Dis Child 2006:91:212-13.

6 Bonati M, Breitkreutz J, Choonara I, et al. Paediatric clinical pharmacology in Europe. Paed Perinat Drug Ther 2006;7:134-7.

7 Anderson M, Choonara I, Ito S, et al. Paediatric clinical pharmacology training programmes in Canada and the UK: a comparison. Paed Perinat Drug Ther 2007;8:26-30.

8 Bonati M, Choonara I, Hoppu K, et al. Closing the gap in drug therapy. Lancet 1999;353:1625.

9 Hawcutt DB, Rose AC, Fuerst-Rektenwald S, et al. Points to consider when planning collection of blood and tissue samples in clinical trials of investigational medicinal products. Guide to Paediatric Drug Development and Clinical Research. In: Rose K, van den Anker JN, eds. Guide to paediatric drug development and clinical research. Basel: Karger, 2010, 97-110.

10 Roberts R, Rodriguez W, Murphy D, et al. Pediatric drug labelling. Improving the safety and efficacy of pediatric therapies. JAMA 2003;290:905-11.
11 Sammons HM, Gray C, Hudson H, et al. Safety in paediatric clinical trials-a 7-year review. Acta Paediatrica 2008;97:474-7.

12 Nor Aripin KNB, Choonara I, Sammons HM. Systematic review of safety in paediatric drug trials published in 2007. Eur J Clin Pharmacol 2012;68:189-94.

13 Thomson AH. Introduction to clinical pharmacokinetics. Paed Perinat Drug Ther 2000:4:3-11.

14 Zhao W, Lopez E, Biran V, et al. Vancomycin continuous infusion in neonates: dosing optimization and therapeutic drug monitoring. Arch Dis Child 2013;98:449-53

15 Allegaert K, Palmer GM, Anderson BJ. The pharmacokinetics of intravenous paracetamol in neonates: size matters most. Arch Dis Child 2011;96:575-80.

16 Parker AC, Preston T, Heaf D, et al. Inhibition of caffeine metabolism by ciprofloxacin in children with cystic fibrosis as measured by the caffeine breath test. Br J Clin Pharmacol 1994;38:573-6.

17 Sammons H. Ethical issues of clinical trials in children: a European perspective. Arch Dis Child 2009;94:474-7.

18 Kearns GL, Abdel-Rahman SM, Alander SW, et al. Developmental pharmacologydrug disposition, action, and therapy in infants in children. $N$ Eng/ I Med 2003:349:1157-67.

19 de Wildt SN, Kearns GL, Leeder JS, et al. Cytochrome P450 3A. Ontogeny and drug disposition. Clin Pharmacokinet 1999;37:484-505.

20 Anderson GD, Lynn AM. Optimizing pediatric dosing: a developmental pharmacologic approach. Pharmacother 2009;29:680-90.

21 de Wildt SN, Kearns GL, Leeder JS, et al. Glucuronidation in humans. Pharmacogentic and developmental aspects. Clin Pharmacokinet 1999;36:439-52.

22 de Wildt SN, Johnson TN, Choonara I. The effect of age on drug metabolism. Paed Perinat Drug Ther 2003;5:101-6.

23 Mulla $\mathrm{H}$. Understanding developmental pharmacodynamics. Importance for drug development and clinical practice. Pediatr Drugs 2010;12:223-33.

24 Hawcutt DB, Thompson B, Smyth RL, et al. Paediatric pharmacogenomics: an overview. Arch Dis Child 2013;98:232-7.

25 Adam de Beaumais T, Jacqz-Aigrain E. Pharmacogenetic determinants of mercaptopurine disposition in children with acute lymphoblastic leukemia. Eur J Clin Pharmacol 2012;68:1233-42.

26 Choonara I. Aspects of clinical pharmacology in children-pharmacovigilance and safety. Eur J Pediatr 2013;172:577-80.

27 Clarkson A, Choonara I. Surveillance for fatal suspected adverse drug reactions in the UK. Arch Dis Child 2002;87:462-7.

28 Bárzaga Arencibia Z, López Leyva A, Mejías Peña Y, et al. Pharmacovigilance in children in Camagüey Province, Cuba. Eur J Clin Pharmacol 2012;68:1079-84.

29 Hoppu K, Anabwani G, Garcia-Bournissen F, et al. The status of paediatric medicines initiatives around the world — what has happened and what has not? Eur J Clin Pharmacol 2012;68:1-10.

30 Boots I, Sukhai RN, Klein RH, et al. Stimulation programs for pediatric drug research—do children really benefit? Eur J Pediatr 2007;166:849-55.

31 Guffon N, Kibleur Y, Copalu W, et al. Developing a new formulation of sodium phenylbutyrate. Arch Dis Child 2012;97:1081-5.

32 Chappell K, Newman C. Potential tenfold drug overdoses on a neonatal unit. Arch Dis Child Neonatal Ed 2004;89:F483-4.

33 Clavenna A, Bonati M. Differences in antibiotic prescribing in paediatric outpatients. Arch Dis Child 2011;96:590-5.

34 Choonara I. Rational prescribing is important in all settings. Arch Dis Child 2013:98:720

35 Clavenna A, Berti A, Gualandi L, et al. Drug utilisation profile in the Italian paediatric population. Eur J Pediatr 2009;168:173-80.

36 Zhang T, Smith MA, Camp PG, et al. Prescription drug dispensing profiles for one million children: a population-based analysis. Eur I Clin Pharmacol 2013;69:581-8

37 Sturkenboom MCJM, Verhamme KMC, Nicolosi A, et al. Drug use in children: cohort study in three European countries. BMJ 2008;337:a2245.

38 Kaguelidou F, Turner MA, Choonara I, et al. Randomized controlled trials of antibiotics for neonatal infections: a systematic review. Br J Clin Pharmacol 2013;76:21-9.

39 Egunsola 0, Adefurin A, Fakis A, et al. Safety of fluconazole in paediatrics: a systematic review. Eur I Clin Pharmacol 2013;69:1211-21.

40 Krekels EHJ, DeJongh J, van Lingen RA, et al. Predictive performance of a recently developed population pharmacokinetic model for morphine and its metabolites in new datasets of (preterm) neonates, infants and children. Clin Pharmacokinet 2011;50:51-63. 